\title{
Farklı Branş Sporcularında Yaralanma Kaygısının İncelenmesi
}

\author{
DOI: $10.26466 /$ opus.588668
}

\section{Levent Tanyeri*}

* Dr, Öğretim Üyesi., Kafkas Üni., Sarıkamış Beden Eğitimi ve Spor Yüksekokulu/ Kars / Türkiye E-Posta: ireynat10@gmail.com

ORCID: 0000-0002-4356-5832

\section{Öz}

Spor insanoğlu açısından hem fiziksel hem de zihinsel faydalara sahiptir. Bireyler sporu farkl branşlarda gerçekleştirmektedirler. Kimi hobi olarak kimi ise amatör veya profesyonel olarak yapmaktadır. Spor esnasinda bireylerin fiziksel olarak yaralanması söz konusu olmaktadır. Yaralanmaya maruz kalmak bir zaman sonra yaralanma korkusuna dönüşmektedir. Çalışmanın amacı, farklı spor branşı ile ilgilenen sporcularda yaralanma kaygısının demografik değişkenler açısından incelenmesidir. Bu amaç doğrultusunda çalışmaya 117'si erkek, 30'u kadın olmak üzere toplam 147 sporcu katıllım göstermiştir. Çalışmada veri toplama aracı olarak Caz, Kayhan ve Bardakçı (2019) tarafindan uyarlanan "Spor Yaralanması Kayğ Ölçeği" ile araştırmacı tarafından oluşturulan "Kişisel Bilgi Formu" kullanılmıştır. Çalışma bulguları, toplanan verilerin normallik varsayımın (çarpıklık= ,699; basıklık= ,877) sağladığını göstermektedir. Çalışma sonucunda, cinsiyet değiş̧keni ile yaralanma kaygısı arasında anlaml farklılıklar olduğu görülmektedir. Ancak, sporculardan daha önce kol veya bacaktan ameliyat geçirenler ile geçirmeyenler arasinda yaralanma kaygisinın anlamlilk yaratmadı̆̆ belirlenmiştir. Benzer olarak, bireysel veya takım sporu ile ilgilenen sporcular arasında da yaralanma kaygısının anlamlılık yaratmadı̆̆ı sonucuna varılmıştır. Ayrıca anlamlılık düzeyi 0,05 olarak baz alınmıştır.

Anahtar Kelimeler: Sporcu, Yaralanma, Branş 


\title{
Investigation of Injury Anxiety in Different Branches Athletes
}

\begin{abstract}
Sports have both physical and mental benefits for human beings. Individuals perform sports in different branches. Some of them work as a hobby and others as amateur or professional. Physical injury of individuals during sports is at stake. Exposure to injury eventually becomes fear of injury. The aim of this study was to investigate the injury anxiety in terms of demographic variables in athletes interested in different sports branches. For this purpose, a total of 147 athletes (117 male and 30 female) participated in the study. In the study, "Sports Injury Anxiety Scale" adapted by Caz, Kayhan and Bardakçı (2019) and "Personal Information Form" created by the researcher were used as data collection tools. The findings of the study show that the collected data provide the assumption of normality (skewness $=, 699 ; \mathrm{kurtosis}=, 877$ ). As a result of the study, it is seen that there are significant differences between gender variable and injury anxiety. However, it was determined that the anxiety of injury between the athletes who had previous arm or leg surgery and those who did not have any meaningfulness. Similarly, it was concluded that the anxiety of injury was not significant among the athletes interested in individual or team sports. In addition, the level of significance was taken as 0,05 .
\end{abstract}

Keywords: Athletes, Injury, Branch 


\section{Giriş}

Spor, hayatımızın vazgeçilmez bir parçası haline gelmiştir. Bilindiği üzere sportif aktivitelerde yer almak bireylerin kişilik gelişimine katkı sağlar, ayrıca metabolizmayı olumsuz etkileyen stresten kurtulma acısından oldukça önemlidir (Caz, Kayhan ve Bardakçı, 2019). Ancak spor, insan vücudu için faydalı olduğu kadar, kişilerin yaralanmasına/ sakatlanmasına da sebebiyet vermektedir.

Spor yaralanmaları, vücudun tamamının veya bir bölgesinin, normalden fazla bir kuvvetle karşılaşması sonucunda, dayanıklılık sınırlarının aşılmasıyla ortaya çıkan durumları kapsar (Erol ve Karahan, 2006). Spor yaralanmaları en çok kas iskelet sistemini etkilemekle birlikte, kemik ve sinir dokusunu değişik şekil ve derecelerde yaralanmaya uğramaktadır (Powell ve Barber-Foss, 1999).

Groh'a göre spor yapanlarda yaralanma görünme olasılığ1 4.000 kişide bir, ölüm oranı ise 40.000 kişide bir ve büyük bir kaza ile karşılaşma oranı ise 40 kişide bir olduğu bildirilmektedir. Bununla birlikte en sık yaralanmanın görüldüğü spor branşları ise futbol, güreş, hentbol, boks, atletizm ve kayak olduğu saptanmıştır. Spor kazalarında en çok spinal kord yaralanmalarının meydana geldiği tespit edilmiştir. Bu yaralanma sırasıyla futbol, rugby, Amerikan futbolu, hava sporları, judo ve jimnastik olarak takip etmektedir (Sakalli, 2008).

Yapılan çalışmalarda toplumda yıllık spor yaralanması geçirme sıklığının \%1-2 seviyelerinde olduğu ifade edilmektedir (Kalyon, 2000). Sporcularda yaralanmaya maruz kalma stresi, daha sonraki zamanlarda tekrar yaralanma kaygısı taşımalarına yol açmaktadır. Bu nedenle yaralanmaya kalan bir sporcu her seferinde benzer kaygıları taşımaktadır. Ancak kimi sporcular yüksek kimi sporcular ise düşük düzeyde kaygı durumu yaşamaktadırlar.

Bazı araştırmacılar, yüksek kaygı seviyesine sahip sporcuların daha fazla yaralanma geçirdiğini belirtmişlerdir (Ivarsson ve Johnson, 2010). Sporcu performansını olumsuz yönde etkileyen kaygı, bir tehdit altında hissedilen korku ve gerginlik olarak ifade edilebilir (Büyüköztürk, 1997).

Tüm spor dallarında yaralanmaların önlenmesi ve oluşan yaralanmaların uygun bir şekilde tedavi edilmesi başarının elde edilmesinde önemli 
bir yer tutmaktadır. Bunun için de ilgili spor dalında oluşabilecek yaralanmaların ve sakatlıkların neler olabileceğinin önceden bilinmesi, alınacak tedbirler açısından çok önemlidir. Bu düşünceye istinaden çalışmanın amacı, sporcularda yaralanma kaygısının sosyo-demografik değişkenler açısından incelenmesidir.

\section{Yöntem}

\section{Araştırma Grubu}

Çalışmanın evrenini, Doğu Anadolu Bölgesi kapsamındaki şehirlerde ikamet eden ve farklı branşlarda sporculuk hayatlarına devam eden sporucular oluşturmaktadır. Örneklemi ise Kars ilinde ikamet eden ve farklı branşı ile ilgili olan 117'si erkek, 30'u kadın olmak üzere toplam 147 sporcudan oluşmaktadır.

\section{Veri Toplama Aracı}

Caz, Kayhan ve Bardakçı (2019) tarafından geliştirilen "Spor Yaralanması Kaygı Ölçeği" ile araştırmacı tarafından oluşturulan kişisel bilgi formu kullanılmıştır. Bu ölçek, altı alt boyut ve 19 maddeden oluşmaktadır. Beşli Likert tipinde (1: kesinlikle katılmıorum-2: katılmıyorum- 3: kararsızım4: katılıyorum- 5: kesinlikle katılıyorum) puanlanan ölçekte olumsuz (ters) madde yoktur. Kişisel bilgi formu ise; cinsiyet, spor branşı, daha önce ameliyat olma durumu, ilgili spor branşında daha önceden yaralanma olup olmadığı, sporculuk düzeyi ve ilgili spor dalı ile ilgili sorulardan oluşmaktadır.

\section{Verilerin Toplanması}

Veriler, google üzerinden oluşturulan online form (veri toplama arac1) aracılığ ile sporculardan toplanmıştır. Çalışmanın uygulanacağı kişilere öncelikle çalışma ile ilgili bilgi verilmiştir. Çalışmada gönüllü katılım ilkesi esas alınmış ve online olarak veriler toplanmaya başlanmıştır. Toplanan veriler düzenlendikten sonra analiz için bilgisayar ortamına aktarılmıştır. 


\section{Verilerin Analizi}

Araştırma kapsamında toplanan verilere ilk olarak normallik testleri uygulanmıştır. Yapılan analizler, verilerin normal bir dağılıma sahip olduğunu göstermiştir. Bu nedenle parametrik testlerin yapılması uygun görülmüştür. Bu doğrultuda aritmetik ortalama, standart sapma, minimum-maksimum ve çarpıklık ile basıklığın olduğu değerleri gösteren ölçek puan dağılımına yer verilmiştir. Bağımsız iki grup için t-testi ve tekyönlü varyans analizi (ANOVA) uygulanmıştır. Tek yönlü varyans analizi (ANOVA) sonucunda ortaya çıkan istatistiksel farkın hangi gruplardan kaynakladığını belirlemek amacıyla Tukey HSD çoklu karşılaştırma testi uygulanmıştır. Verilerin istatistiksel analizinde ve yorumlarda, $\mathrm{p}<0,05$ anlamlılık düzeyi baz alınmıştır.

\section{Bulgular}

Tablo 1. Ölçek Puan Dağılımı

\begin{tabular}{cccccccc}
\hline Ölçek & N & Min & Max & Ort. & Ss. & Çarpıklık & Basıklık \\
\hline Spor Yaralanması Kaygı & 147 & 19,00 & 95,00 & 2,38 & 16,21 &, 699 &, 877 \\
\hline
\end{tabular}

Spor Yaralanma Kaygısı kapsamında sporculardan toplanan veriler analiz edilmiş ve aldıkları puanların aritmetik ortalaması 2,38 çıkmıştır. $\mathrm{Bu}$ değer, sporcuların yaralanma kaygılarının düşük olduğunu göstermektedir. Ayrıca ölçeğin Çarpıklık (,699) ve Basıklık (,877) katsayıları incelendiğinde verilerin normal bir dağılıma sahip olduğu görülmektedir (Tablo 1).

Tablo 2. Spor Yaralanma Kaygısının Cinsiyet değişkeni Sonucu

\begin{tabular}{|c|c|c|c|c|c|c|}
\hline Ölçek ve Alt Boyutları & Cinsiyet & $\mathbf{N}$ & Ort. & Ss. & $\mathbf{t}$ & p \\
\hline \multirow{2}{*}{$\begin{array}{c}\text { Yeteneğini Kaybetme } \\
\text { Kaygısı }\end{array}$} & Erkek & 117 & 6,70 & 3,59 & \multirow[t]{2}{*}{2,053} & \multirow[t]{2}{*}{, 044} \\
\hline & Kadın & 30 & 5,53 & 2,55 & & \\
\hline \multirow{2}{*}{$\begin{array}{c}\text { Zayıf Algilanma } \\
\text { Kaygısı } \\
\end{array}$} & Erkek & 117 & 6,26 & 3,48 & \multirow[t]{2}{*}{1,577} & \multirow[t]{2}{*}{120} \\
\hline & Kadın & 30 & 5,40 & 2,42 & & \\
\hline \multirow[t]{2}{*}{ Acı Çekme Kaygısı } & Erkek & 117 & 8,59 & 3,49 & \multirow[t]{2}{*}{ 113 } & \multirow[t]{2}{*}{,910 } \\
\hline & Kadın & 30 & 8,53 & 2,59 & & \\
\hline \multirow{2}{*}{$\begin{array}{l}\text { Hayal Kırıklığına } \\
\text { Uğratma Kaygısı }\end{array}$} & Erkek & 117 & 7,97 & 3,62 & \multirow[t]{2}{*}{2,369} & \multirow[t]{2}{*}{,019 } \\
\hline & Kadın & 30 & 6,26 & 3,06 & & \\
\hline \multirow{2}{*}{$\begin{array}{c}\text { Sosyal Desteği } \\
\text { Kaybetme Kaygisı }\end{array}$} & Erkek & 117 & 5,94 & 3,44 & \multirow[t]{2}{*}{2,350} & \multirow[t]{2}{*}{,020 } \\
\hline & Kadın & 30 & 4,40 & 1,95 & & \\
\hline
\end{tabular}




\begin{tabular}{cllllll}
\hline Yeniden Yaralanma & Erkek & 117 & 10,00 & 3,99 & \multirow{2}{*}{728} & \multirow{2}{*}{468} \\
\cline { 2 - 5 } Kaygısı & Kadın & 30 & 9,43 & 2,89 & & \\
\hline Spor Yaralanması & Erkek & 117 & 46,32 & 17,30 & \multirow{2}{*}{2,210} & \multirow{2}{*}{$\mathbf{0 3 0}$} \\
Kaygı Toplamı & Kadın & 30 & 40,93 & 10,08 & & \\
\hline
\end{tabular}

Tablo 2, kadın ve erkek sporcuların yaralanma kaygısı incelendiğinde Spor Yaralanması Kaygı ölçeğinin "Yeteneğini Kaybetme Kaygısı", "Hayal Kırıklığına Uğratma Kaygısı" ve "Sosyal Desteği Kaybetme Kaygisı" alt boyutu ile ölçeğin toplam puanında istatistiksel olarak anlamlı farklılıklar tespit edilmiştir $(\mathrm{p}<0,05)$.

Tablo 3. Spor Yaralanma Kaygısının Branş değişkeni Sonucu

\begin{tabular}{|c|c|c|c|c|c|c|c|}
\hline $\begin{array}{l}\text { Ölçek ve Alt } \\
\text { Boyutlar }\end{array}$ & Branş & $\mathbf{N}$ & Ort. & Ss. & $\mathbf{F}$ & p & $\begin{array}{c}\text { Anlamlı } \\
\text { Çıkan Gru- } \\
\text { plar }\end{array}$ \\
\hline Yeteneğini & Futbol & 96 & 6,71 & 3,54 & \multirow{3}{*}{1,678} & \multirow{3}{*}{ 190 } & \multirow{3}{*}{----- } \\
\hline Kaybetme & Basketbol & 18 & 5,11 & 3,37 & & & \\
\hline Kaygisı & Voleybol & 33 & 6,48 & 3,02 & & & \\
\hline Zayıf & Futbol & 96 & 6,40 & 3,45 & \multirow{3}{*}{1,668} & \multirow{3}{*}{ 192 } & \multirow{3}{*}{----- } \\
\hline Algilanma & Basketbol & 18 & 4,94 & 2,94 & & & \\
\hline Kaygisı & Voleybol & 33 & 5,78 & 2,95 & & & \\
\hline & Futbol & 96 & 8,54 & 3,34 & \multirow{3}{*}{,027 } & \multirow{3}{*}{ 973 } & \multirow{3}{*}{----- } \\
\hline Acı Çekme & Basketbol & 18 & 8,72 & 3,75 & & & \\
\hline Kaygisı & Voleybol & 33 & 8,63 & 3,13 & & & \\
\hline Hayal & Futbol (1) & 96 & 8,02 & 3,38 & \multirow{3}{*}{3,401} & \multirow{3}{*}{,036 } & \multirow{3}{*}{$1>2$} \\
\hline $\begin{array}{l}\text { Kırıklığına } \\
\text { Uğratma }\end{array}$ & Basketbol(2) & 18 & 5,66 & 3,27 & & & \\
\hline Kaygis1 & Voleybol & 33 & 7,54 & 4,00 & & & \\
\hline Sostal & Futbol & 96 & 6,06 & 3,44 & \multirow{3}{*}{2,675} & \multirow{3}{*}{,072 } & \multirow{3}{*}{----- } \\
\hline Desteği Kaybetme & Basketbol & 18 & 4,50 & 3,01 & & & \\
\hline Kaygisi & Voleybol & 33 & 4,96 & 2,55 & & & \\
\hline Yeniden & Futbol & 96 & 9,88 & 4,06 & \multirow{3}{*}{,002 } & \multirow{3}{*}{ 998 } & \multirow{3}{*}{----- } \\
\hline Yaralanma & Basketbol & 18 & 9,83 & 3,63 & & & \\
\hline Kaygis1 & Voleybol & 33 & 9,90 & 3,10 & & & \\
\hline Spor Yaralanması & Futbol & 96 & 46,64 & 16,89 & \multirow{3}{*}{1,530} & \multirow{3}{*}{220} & \multirow{3}{*}{---- } \\
\hline Kayg1 & Basketbol & 18 & 39,61 & 16,87 & & & \\
\hline Toplamı & Voleybol & 33 & 44,15 & 13,27 & & & \\
\hline
\end{tabular}

Sporcuların ilgilenmiş oldukları branşlar ile yaralanma kaygıları arasındaki farklılıklar incelenmiş ve Yaralanma kaygısının sadece "Hayal Kırıklığına Uğratma Kaygısı" alt boyutunda anlamlı farklılık tespit edilmiştir $(p<0,05)$. Analiz sonucu oluşan farklılığın hangi gruplar arasında kaynaklandığının tespiti için çoklu karşılaştırma testlerinden 
Tukey testi gerçekleştirilmiş ve farklılığın Futbol ile Basketbol branş sporcuları arasında ortaya çıkmıştır.

Tablo 4. Spor Yaralanma Kaygısının Bacak veya Kollardan Ameliyat Geçirilip Geçirilmediğine Dair Analiz Sonucu

\begin{tabular}{|c|c|c|c|c|c|c|}
\hline Ölçek ve Alt Boyutları & Ameliyat Olmak & $\mathbf{N}$ & Ort. & Ss. & $t$ & $\mathrm{p}$ \\
\hline Yeteneğini & Evet & 19 & 6,78 & 4,02 & \multirow[t]{2}{*}{434} & \multirow[t]{2}{*}{ 665 } \\
\hline Kaybetme Kaygisı & Hayır & 128 & 6,42 & 3,35 & & \\
\hline Zayıf Algılanma & Evet & 19 & 6,63 & 4,39 & \multirow[t]{2}{*}{,596 } & \multirow[t]{2}{*}{,558 } \\
\hline Kaygis1 & Hayır & 128 & 6,00 & 3,13 & & \\
\hline Acl Çekme & Evet & 19 & 9,05 & 3,27 & \multirow[t]{2}{*}{,656 } & \multirow[t]{2}{*}{, 513} \\
\hline Kaygisı & Hayır & 128 & 8,51 & 3,33 & & \\
\hline Hayal Kırıklığına & Evet & 19 & 8,47 & 4,08 & \multirow[t]{2}{*}{1,108} & \multirow[t]{2}{*}{,270 } \\
\hline Uğratma Kaygısı & Hayır & 128 & 7,50 & 3,49 & & \\
\hline Sosyal Desteği & Evet & 19 & 6,26 & 3,73 & \multirow[t]{2}{*}{,915 } & \multirow[t]{2}{*}{,362 } \\
\hline Kaybetme Kaygisı & Hayır & 128 & 5,53 & 3,17 & & \\
\hline Yeniden & Evet & 19 & 11,34 & 3,78 & \multirow[t]{2}{*}{1,841} & \multirow[t]{2}{*}{,068 } \\
\hline Yaralanma Kaygisı & Hayır & 128 & 9,66 & 3,76 & & \\
\hline Spor Yaralanması & Evet & 19 & 49,13 & 18,10 & \multirow[t]{2}{*}{1,119} & \multirow[t]{2}{*}{,265 } \\
\hline Kaygı Toplamı & Hayır & 128 & 44,64 & 15,91 & & \\
\hline
\end{tabular}

Sporcuların bacak veya kollardan herhangi bir ameliyat yaşayıp yaşamadıkları ile spor yaralanması kaygısı arasındaki farklılığa bakıldığında, daha önce bacak veya kollardan herhangi ameliyata maruz kalan ile kalmayan sporular arasında herhangi bir farklılık tespit edilememiştir ( $\mathrm{p}>0,05)$, (Tablo 4).

Tablo 5. Spor Yaralanma Kaygısının Daha Önce Herhangi Bir Yaralanma Yaşanıp Yaşanmadiğına Dair Analiz Sonucu

\begin{tabular}{|c|c|c|c|c|c|c|}
\hline Ölçek ve Alt Boyutlar & Yaralanma Yaşamak & $\mathbf{N}$ & Ort. & Ss. & $t$ & $\mathrm{p}$ \\
\hline $\begin{array}{l}\text { Yeteneğini } \\
\end{array}$ & Evet & 75 & 6,97 & 3,61 & \multirow[t]{2}{*}{1,831} & \multirow[t]{2}{*}{, 069} \\
\hline Kaybetme Kaygisı & Hayır & 72 & 5,94 & 3,17 & & \\
\hline Zayıf Algılanma & Evet & 75 & 6,68 & 3,75 & \multirow[t]{2}{*}{2,257} & \multirow[t]{2}{*}{,026 } \\
\hline Kaygisı & Hayır & 72 & 5,47 & 2,65 & & \\
\hline \multirow[t]{2}{*}{ Acı Çekme Kaygısı } & Evet & 75 & 9,10 & 3,21 & \multirow[t]{2}{*}{1,960} & \multirow[t]{2}{*}{,049 } \\
\hline & Hayır & 72 & 8,04 & 3,37 & & \\
\hline Hayal Kırıklığına & Evet & 75 & 8,17 & 3,69 & \multirow[t]{2}{*}{1,911} & \multirow[t]{2}{*}{2058} \\
\hline Uğratma Kaygisı & Hayır & 72 & 7,05 & 3,38 & & \\
\hline Sosyal Desteği & Evet & 75 & 6,33 & 3,37 & \multirow[t]{2}{*}{2,752} & \multirow[t]{2}{*}{,007 } \\
\hline Kaybetme Kaygisı & Hayır & 72 & 4,88 & 2,96 & & \\
\hline Yeniden Yaralanma & Evet & 75 & 10,88 & 3,89 & \multirow[t]{2}{*}{3,359} & \multirow[t]{2}{*}{, 001 } \\
\hline Kaygisı & Hayır & 72 & 8,84 & 3,42 & & \\
\hline Spor Yaralanması & Evet & 75 & 48,86 & 17,17 & \multirow[t]{2}{*}{2,846} & \multirow[t]{2}{*}{,005 } \\
\hline Kaygı Toplamı & Hayır & 72 & 41,43 & 14,31 & & \\
\hline
\end{tabular}


Sporcuların daha önce herhangi bir yaralanma yaşayıp yaşamadıkları bir durum ile yaralanması kaygısı arasındaki farklılığa bakıldığında anlamlı farklılıkların oluştuğu görülmektedir. Ölçeğin "Zayıf Algılanma Kaygisı", “Acı Çekme Kaygısı", "Sosyal Desteği Kaybetme Kaygısı", “Yeniden Yaralanma Kaygısı" ve ölçeğin toplam puanında manidar farklıklar tespit edilmiştir $(\mathrm{p}<0,05)$. Bulgulara bakıldığında bu farklılığın daha önce yaralanma yaşayanlar lehine çıkmış olduğu anlaşılmaktadır.

Tablo 6. Spor Yaralanma Kaygısının Sporculuk Düzeyi değişkeni Analiz Sonucu

\begin{tabular}{|c|c|c|c|c|c|c|}
\hline Ölçek ve Alt Boyutları & $\begin{array}{c}\text { Sporculuk } \\
\text { Düzeyi }\end{array}$ & $\mathbf{N}$ & Ort. & Ss. & $\mathbf{t}$ & p \\
\hline Yeteneğini & Amatör & 124 & 6,55 & 3,41 & \multirow[t]{2}{*}{ 713 } & \multirow[t]{2}{*}{,477 } \\
\hline Kaybetme Kaygisı & Profesyonel & 23 & 6,00 & 3,54 & & \\
\hline Zayıf Kaygisı & Amatör & 124 & 6,12 & 3,22 & \multirow[t]{2}{*}{276} & \multirow[t]{2}{*}{,783 } \\
\hline Kaygisi & Profesyonel & 23 & 5,91 & 3,80 & & \\
\hline Acı Çekme & Amatör & 124 & 8,32 & 3,20 & \multirow[t]{2}{*}{$-2,253$} & \multirow[t]{2}{*}{,026 } \\
\hline Kaygısı & Profesyonel & 23 & 10,00 & 3,64 & & \\
\hline Hayal Kırıklığına & Amatör & 124 & 7,67 & 3,55 & \multirow[t]{2}{*}{405} & \multirow[t]{2}{*}{ 686 } \\
\hline Uğratma Kaygısı & Profesyonel & 23 & 7,34 & 3,77 & & \\
\hline Sosyal Desteği & Amatör & 124 & 5,57 & 3,06 & \multirow[t]{2}{*}{,- 370} & \multirow[t]{2}{*}{714} \\
\hline Kaybetme Kaygısı & Profesyonel & 23 & 5,91 & 4,20 & & \\
\hline Yeniden & Amatör & 124 & 9,67 & 3,67 & \multirow[t]{2}{*}{$-1,542$} & \multirow[t]{2}{*}{,125 } \\
\hline Yaralanma Kaygisı & Profesyonel & 23 & 11,00 & 4,28 & & \\
\hline Spor Yaralanması & Amatör & 124 & 44,87 & 15,62 & \multirow[t]{2}{*}{,- 598} & \multirow[t]{2}{*}{,551 } \\
\hline Kaygı Toplamı & Profesyonel & 23 & 47,08 & 19,37 & & \\
\hline
\end{tabular}

Tablo 6, sporculuk düzeyi değişkeni hakkında bilgi vermektedir. Yaralanma kaygisının sadece "Acı Çekme Kaygısı" alt boyutunda anlamlı farklılık tespit edilmişken $(p<0,05)$, diğer alt boyutlar ve ölçeğin toplam puanında herhangi bir farklılık gözlenmemiştir $(p>0,05)$.

Tablo 7. Spor Yaralanma Kaygısının Spor Dalı Değişkeni Analiz Sonucu

\begin{tabular}{|c|c|c|c|c|c|c|}
\hline Ölçek ve Alt boyutları & Spor Dalı & $\mathbf{N}$ & Ort. & Ss. & $t$ & $p$ \\
\hline Yeteneğini & Bireysel & 44 & 6,47 & 3,49 & \multirow[t]{2}{*}{, 018 } & \multirow[t]{2}{*}{,986 } \\
\hline Kaybetme Kaygisı & Takım & 103 & 6,46 & 3,42 & & \\
\hline \multirow{2}{*}{$\begin{array}{c}\text { Zayıf Algilanma } \\
\text { Kaygisı }\end{array}$} & Bireysel & 44 & 5,59 & 3,03 & \multirow[t]{2}{*}{$-1,193$} & \multirow[t]{2}{*}{235} \\
\hline & Takım & 103 & 6,30 & 3,41 & & \\
\hline \multirow[t]{2}{*}{ Acı Çekme Kaygısı } & Bireysel & 44 & 9,18 & 3,49 & \multirow[t]{2}{*}{1,428} & \multirow[t]{2}{*}{ 156 } \\
\hline & Takım & 103 & 8,33 & 3,23 & & \\
\hline Hayal Kırıklığına & Bireysel & 44 & 6,77 & 3,55 & \multirow[t]{2}{*}{$-1,907$} & \multirow[t]{2}{*}{,059 } \\
\hline Uğratma Kaygısı & Takım & 103 & 7,99 & 3,54 & & \\
\hline
\end{tabular}




\begin{tabular}{ccccccc}
\hline Sosyal Desteği & Bireysel & 44 & 5,11 & 3,10 & \multirow{2}{*}{$-1,250$} & \multirow{2}{*}{, 213} \\
\cline { 2 - 5 } Kaybetme Kaygısı & Takım & 103 & 5,84 & 3,30 & & \\
\hline Yeniden & Bireysel & 44 & 10,36 & 3,36 & \multirow{2}{*}{1,001} & \multirow{2}{*}{, 319} \\
\cline { 2 - 5 } Yaralanma Kaygısı & Takım & 103 & 9,67 & 3,96 & & \\
\hline $\begin{array}{c}\text { Spor Yaralanması } \\
\text { Kaygı Toplamı }\end{array}$ & Bireysel & 44 & 44,45 & 16,06 & \multirow{2}{*}{,- 375} & \multirow{2}{*}{, 708} \\
\cline { 2 - 5 } & Takım & 103 & 45,55 & 16,35 & & \\
\hline
\end{tabular}

Spor dalı değişkeni incelendiğinde bireysel ve takım sporları ile ilgilenen sporcular arasında yaralanma kaygisı anlamında herhangi bir farklılık oluşmamıştır ( $\mathrm{p}>0,05)$, (Tablo 7).

\section{Tartışma}

Mevcut çalışmada kadın ve erkek sporcuların yaralanma kaygısı incelendiğinde Spor Yaralanması Kaygı ölçeğinin "Yeteneğini Kaybetme Kaygısı", "Hayal Kırıklığına Uğratma Kaygısı" ve "Sosyal Desteği Kaybetme Kaygısı" alt boyutu ile ölçeğin toplam puanında istatistiksel olarak anlamlı farklılıklar tespit edilmiştir.

Sporcuların ilgilenmiş oldukları branşlar ile yaralanma kaygıları arasındaki farklılıklar incelenmiş ve Yaralanma kaygısının sadece "Hayal Kırıklığına Uğratma Kaygısı" alt boyutunda anlamlı farklılık tespit edilmiştir. Bu farklılığın Futbol ile Basketbol branş sporcuları arasında ortaya çıkmıştır. Benzer bir sonuç, futbol yaralanmalarının en sık rakip oyuncu tarafından yapılan engellemeler ve top kapmalar esnasında meydana geldiği belirlenmiştir (Zoch ve ark., 1996). Spor yaralanmaları arasında futbolda meydana gelen yaralanmaların önemli bir yer tuttuğu bilinmektedir (Engstrom ve ark., 1991). Sonne ve arkadaşları (1980), değişik spor branşlarında görülen sakatlanmaları futbol'da \%40.00 hentbol'da \%27.00 (16), Doğan ve İmamoğlu (1995) futbol'da \%46.06, hentbol'da \%38.06, basketbol'da \%25.03, voleybol da \%17.03 olarak bildirmişlerdir (Sonne ve ark., 1980).

Sporcuların bacak veya kollardan herhangi bir ameliyat yaşayıp yaşamadıkları ile spor yaralanması kaygısı arasındaki farklılığa bakıldığında, daha önce bacak veya kollardan herhangi ameliyata maruz kalan ile kalmayan sporular arasında herhangi bir farklılık tespit edilememiştir. Ancak Strauss, toplam 1908 güreşçi üzerinde yaptığ 1 çalışmasında diz ve ayak bileği sakatlıklarının oldukça yaygın olduğunu 
gözlemlemiş (Strauss, 1982). Lorish ve arkadaşları ise 6-16 yaş arasındaki 1742 güreşçi üzerinde yaptıkları bir araştırmada yaralanmaların daha çok üst ekstremitelerde, boyun ve sırt bölgelerinde olduğunu belirtmişlerdir (Lorish ve ark., 1992). Spor yaralanmaları hakkında yapılan diğer çalışmalar neticesinde vücutta en fazla etkilenen bölgenin alt ekstremiteler olduğu ve en sık da ayak bileği ve diz bölgesinin yaralandığı saptanmıştır. Spor yaralanmalarının en sık burkulma, kontüzyon, abrazyon, incinme ve kırık olduğu belirtilmiştir (Powell, 1992). Alt ekstremite de en fazla yaralanmanın ayak ve ayak bileği bölgesinde (46 yaralanma, \% 20,72) oluştuğu görülmektedir. Literatürde de futbolda yaralanmaların daha çok alt ekstremitede, özellikle de diz ve ayak bileği bölgesinde oluştuğunu ortaya koyan benzer çalışmalar yer almaktadır(Cromwell ve ark., 2000). Oluşan sakatlıkların vücut bölgelerine göre dağılımı incelendiğinde tüm branşlarda en fazla sakatlanan bölgenin ayak ve ayak bileği olduğu, ancak güreşte birinci sırada diz sakatlıklarının geldiği tespit edilmiştir. Bu bulgular, literatürdeki bulgular ile uyumludur (Meeuwisse ve ark., 2000).

\section{Sonuç}

Çalışma kapsamında toplanan verilerin analizi, yaralanma kaygı düzeyi ortalama puanının düşük olduğunu göstermektedir. Ortalama puanın düşük olması, sporcuların yaralanma kaygılarının düşük olduğunu ifade etmektedir. Ayrıca, verilerin normal bir dağılıma sahip olduğu da tespit edilmiştir.

Cinsiyet değişkeni sonucu, kadın ve erkek sporcuların yaralanma kayg1 düzeylerinin farklı alt boyutlarda erkek sporcular lehine anlamlı farklılıklar çıktığını göstermiştir. Bu sonuç erkek sporcuların yaralanma kaygılarının daha yüksek olduğunu ifade etmektedir. Erkek sporcuların kaygı düzeylerinin yüksek çıkmasında kadınlara oranla fiziksel olarak daha güçlü, kuvvetli olmaları ve fiziksel temas gerektiren branşlarda rakibine daha sert müdahalelerde bulunuyor olmaları sebebiyet vermektedir.

Sporcuların ilgilenmiş oldukları branş ile yaralanma kaygıları arasındaki farklılıklar incelenmiş ve yaralanma kaygısının sadece "Hayal Kırıklığına Uğratma Kaygısı" alt boyutunda anlamlı farklılık tespit edilmiştir. Futbol ve basketbol sporcularında oluşan farklılı̆̆ın futbolcular 
lehine yüksek çımasında oynanan oyunun süresi, fiziksel temas gerektirmesi, daha sert müdahalelerin oyun içerisinde yer alması gibi faktörler etken olmaktadır.

Sporcuların bacak veya kollardan herhangi bir ameliyat yaşayıp yaşamadıkları ile yaralanma kaygısı arasındaki farklılığa bakıldığında, daha önce bacak veya kollardan herhangi ameliyata maruz kalan ile kalmayan sporular arasında herhangi bir farklılık tespit edilememiştir. $\mathrm{Bu}$ bulgu, ameliyata maruz kalma değişkeninin yaralanma kaygısı üzerinde anlamlı etkisinin olmadığını göstermektedir.

Sporcuların önceki zamanlarda herhangi bir yaralanma yaşayıp yaşamadıkları ile yaralanma kaygısı arasındaki farklıı̆̆a bakıldığında anlamlı farklılıkların oluştuğu görülmektedir. Bulgular, bu farklılı̆̆ın daha önce yaralanma yaşayanlar lehine çıkmış olduğunu göstermiştir. Önceki süreçte yaralanmanın sporcular üzerinde tekrardan yaralanma kaygısını arttırdığı sonucuna ulaşılmıştır.

Sporculuk düzeyi değişkeninin yaralanma kaygısı üzerindeki etkisine bakıldığında "acı çekme kaygısı" alt boyutunda anlamlı farklılık tespit edilmiştir. Ancak, diğer alt boyutlar ve ölçeğin toplam puanında herhangi bir farklılık gözlenmemiştir. Bu bulgu genel olarak amatör ya da profesyonel olarak sporculuk hayatını sürdürmenin spor yaralanması kaygı düzeyinde anlamlı etkisinin olmadığını göstermektedir. Spor dalı değişkeni incelendiğinde ise bireysel ve takım sporları ile ilgilenen sporcular arasında yaralanma kaygısı anlaminda herhangi bir farklılık oluşmadığı tespit edilmiştir. 


\title{
EXTENDED ABSTRACT
}

\section{Investigation of Injury Anxiety in Different Branches Athletes}

\author{
Levent Tanyeri \\ Kafkas University
}

Sport has become an indispensable part of our lives. As it is known, taking part in sports activities contributes to the personality development of individuals and it is also very important in terms of getting rid of stress which affects metabolism negatively (Caz, Kayhan and Bardakçı, 2019). Sports injuries, the entire body or a region, as a result of encountering a force more than normal, occurs when the endurance limits are exceeded (Erol and Karahan, 2006). Some researchers reported that high-anxiety athletes suffer more injuries (Ivarsson and Johnson, 2010). Anxiety that adversely affects athlete performance can be expressed as fear and tension under a threat (Büyüköztürk, 1997). Prevention of injuries and proper treatment of injuries in all sports branches play an important role in achieving success. For this reason, it is very important to know in advance what the injuries and disabilities may be in the related sports branch in terms of the measures to be taken.

The study group consisted of 147 athletes, 117 of whom were men and 30 of whom were athletes. "Sport Injury Anxiety Scale developed by Caz, Kayhan and Bardakçı (2019) and personal information form created by the researcher were used. This scale consists of six sub-dimensions and 19 items. There is no negative (reverse) item on the scale scored in the Likert type of five (1: strongly disagree-2: disagree- 3: undecided- 4: agree- 5: strongly agree). Personal information form; gender, sports branch, the status of previous surgery, whether there was a previous injury in the sports branch, the level of sportsmanship and the related sport.

Data was collected from athletes through the online form (data collection tool) created on google. First of all, information about the study was given to the persons to whom the study will be applied. The study was 
based on the principle of voluntary participation and online data collection was started. The collected data were edited and transferred to computer for analysis.

Firstly, normality tests were applied to the data collected within the scope of the research. The analysis showed that the data had a normal distribution. Therefore, parametric tests were considered appropriate. In this respect, the scale score distribution showing arithmetic mean, standard deviation, minimum-maximum and skewness and kurtosis values are included. For two independent groups, t-test and one-way analysis of variance (ANOVA) were performed. Tukey HSD multiple comparison test was applied in order to determine the groups from which the statistical difference resulting from one-way analysis of variance (ANOVA) originated. Statistical analysis and interpretation of the data were based on $p$ $<0.05$ significance level.

The analysis of the data collected from the athletes shows that the athletes' anxiety concerns are low. Considering the gender variable, significant differences were found in favor of male athletes in different sub-dimensions of injury anxiety of female and male athletes. This result shows that male athletes have higher injury anxiety. The high levels of anxiety are caused by the fact that male athletes are physically stronger, stronger, and in the branches that require physical contact, the men intervene more harshly against their competitors.

The differences between the branches that the athletes were interested in and the injury anxiety were examined and a significant difference was found only in one sub-dimension of the injury anxiety. Factors such as the duration of the game played, the need for physical contact and the involvement of harder interventions in the game play a role in increasing the anxiety level in favor of the players due to the difference in football and basketball athletes.

Looking at the difference between whether the athletes had any operation on the leg or arms and the anxiety of sports injury, no difference could be detected between those who had previously undergone any operation on the leg or arms and who did not. This finding indicates that the surgical exposure variable has no significant effect on injury anxiety.

When the difference between the athletes' previous injury and injury anxiety is seen, it is seen that there are significant differences. When the 
findings are examined, it is understood that this difference was in favor of those who had previously suffered injuries. In the previous process, it was concluded that the injury increased the anxiety of injury on the athletes.

When the effect of athletic level variable on injury anxiety was examined, a significant difference was found in a sub-dimension. However, no difference was observed in the other sub-dimensions and the total score of the scale. This finding demonstrates that generally, amateur or professional life does not have a significant effect on sports injury. When the sport branch variable was examined, it was found that there was no difference between the athletes interested in individual and team sports in terms of injury anxiety.

\section{Kaynakça / References}

Büyüköztürk, Ş. (1997). Araştırmaya yönelik kaygı ölçeğinin geliştirilmesi. Kuram ve Uygulamada Eğitim Yönetimi, 3(4), 453-64.

Caz, Ç., Kayhan, R.F. ve Bardakçı, S. (2019). Spor yaralanması kaygı ölçeği'nin Türkçeye uyarlanması: Geçerlik ve güvenirlik çalışması. Spor Hekimliği Dergisi, 54(1), 52-63.

Cromwell, F., Gormley, J., Walsh J. (2000) A pilot study examining injuries in elite gaelic footballers. Br. J. Sports Med, 24(2), 104-112.

Erol, B. ve Karahan, M. (2006). Çocuklarda spor yaralanmaları. Türkiye Klinikleri J Pediatr Sci, 2(4), 89-97.

Engstrom, B., Johanson, C. ve Tornkvist, H. (1991). Soccer injuries among elite female player. J Sports Med. 19(4), 372-377.

Ivarsson, A. ve Johnson, U. (2010). Psychological factors a predictors of injuries among senior soccer players: a prospective study. J Sports Sci Med. $9(2), 347-52$.

Kalyon, T.A. (2010). Spor yaralanmaları. (T.A. Kalyon ed). Spor Hekimliği, Sporcu Sağlığı Ve Spor Sakatlıkları içinde (s.183-186). Ankara: GATA Basımevi.

Lorish, T.R, Rizzo, T.D. ve Iltstrup, D.M. (1992). Injuries adolescent and préadolescent boys at two Large wrestling tournaments Am J Spors Med, 20(2), 199-202.

Meeuwisse, W.H., Hagel, B.E., Mohtadi, N.G., Butterwick, D.J. ve Fick, G.H. (2000). The distribution of injuries in men's canada west university 
football. A 5-year analysis. The American Journal of Sport Medicine, 28, 516-523.

Powell, J.W. ve Barber-Foss K.D. (1999). Injury patterns in selected high school sports: A review of the 1995-1997 seasons. J Athl Train. 34, 277-284.

Sakallı, F.M.H. (2008). Sporda sporcuların yaralanması ve risk faktörleri. Fırat Sağlık Hizmetleri Dergisi, 3(7), 144-154.

Sonne, S. ve Sorenson, C.H. (1980). Risk factors with acute sports injuries. British Journal of Sport Medicine, 14, 22-25.

Strauss, R.H. (2016). Injuries among wrestlers in school and college tournaments. Jama, 248(16), xxx-xxx.

Zoch, T.W. ve Cleveland, D.A. (1996). Football injuries in a rural area. Wis Med $J, 95,570-573$.

\section{Kaynakça Bilgisi / Citation Information}

Tanyeri, L. (2019). Farklı branş sporcularında yaralanma kaygısının incelenmesi. OPUS-Uluslararası Toplum Araştırmaları Dergisi, 13(19), 577-591. DOI: 10.26466/opus.588668 